\title{
Expression of NLRC4 in children with septicaemia and mechanisms of NLRC4 in in vitro cytokine secretion
}

\author{
GUOJI ZHU $^{1 *}$, JING CHEN $^{1 *}$, JIANMEI TIAN $^{1}$, LINGQING GE $^{1}$, AIXIA XING $^{2}$ and GUANGMING TANG ${ }^{1}$ \\ ${ }^{1}$ Department of Internal Medicine, Soochow University Affiliated Children's Hospital, Suzhou, Jiangsu 215003; \\ ${ }^{2}$ Department of Internal Medicine, The Second Affiliated Hospital of Nantong University, \\ Nantong, Jiangsu 226001, P.R. China
}

Received May 22, 2015; Accepted April 6, 2016

DOI: $10.3892 / \mathrm{mmr} .2016 .5254$

\begin{abstract}
Septicaemia, a systemic bacterial infection, frequently leads to morbidity and mortality in children. The NOD-like receptor (NLR) family, CARD domain containing 4 (NLRC4) is involved in the control of infections. The aim of the present study was to detect the expression of NLRC4 in the blood samples of children with septicaemia, in addition to investigating the importance of NLRC4 in cytokine production, and the signaling pathways that regulate NLRC4 expression in lipopolysaccharide (LPS)-stimulated macrophages. It was determined that when compared with the control, the mRNA and protein expression levels of NLRC4 were significantly increased in the blood samples of children with septicaemia, as demonstrated by the reverse transcription-quantitative polymerase chain reaction and western blot analysis. The results from the western blotting indicated that treatment with LPS induced NLRC4 expression in a time- and dose-dependent manner in RAW264.7 cells. A knockdown of NLRC4 by siRNA transfection enhanced the effect of LPS on interleukin (IL)-1 $\beta$ and IL-18 production, as determined by enzyme-linked immunosorbent assay. Inhibitors of extracellular regulated protein kinases, c-Jun N-terminal kinases and p38 were used in the present study to block the mitogen-activated protein kinase (MAPK) signaling pathway, and it was determined that LPS-induced NLRC4 expression was reversed by the suppression of the MAPK signaling pathway. To the best of our knowledge, this is the first report regarding the expression of NLRC4 in children with septicaemia. Furthermore, a novel molecular mechanism for NLRC4 regulation in LPS-induced RAW264.7 macrophage cells has been elucidated. The data in the present study supports
\end{abstract}

Correspondence to: Professor Jianmei Tian, Department of Internal Medicine, Soochow University Affiliated Children's Hospital, 303 Jingde Road, Suzhou, Jiangsu 215003, P.R. China E-mail: jianmei_t@yeah.net

*Contributed equally

Key words: NLRC4, septicaemia, mitogen-activated protein kinase, lipopolysaccharide the hypothesis that LPS activates the MAPK pathway in macrophages, thus resulting in the upregulation of NLRC4; however, NLRC4 inhibits IL-1 $\beta$ and IL-18 production, contributing to the anti-inflammatory response.

\section{Introduction}

Septicaemia is a systemic bacterial infection resulting from the spread of microorganisms and their toxins in the blood (1). Although modern medical technology has improved greatly in recent years, septicaemia often leads to morbidity and mortality in children in developing countries (2). Therefore, it is necessary to explore the risk factors, which influence the prognosis of children with septicaemia.

NOD-like receptor (NLR) family, CARD domain-containing protein 4 (NLRC4) was initially described in 2001, and demonstrated to detect cytosolic flagellin (3-5). NLRC4 is a key component of the inflammasome response to a variety of microbial stimuli and endogenous danger signals via caspase-1 activation, cytokine production and macrophage pyroptosis (6-9). NLRC4 is involved in the control of infections. A number of bacteria have been demonstrated to prompt caspase-1 activation and the inflammatory cytokines interleukin (IL)-1 $\beta$ and IL-18 maturation via the activation of NLRC4 (7,10-13). However, the molecular mechanisms underlying the importance of NLRC4 in the immune response of macrophages have not been thoroughly investigated.

The present study detected the expression of NLRC4 for, to the best of our knowledge, the first time in the blood samples of children with septicaemia. Furthermore, an in vitro investigation was performed on lipopolysaccharide (LPS)-stimulated RAW264.7 macrophage cells in order to investigate the effect of NLRC4 in cytokine production and the signaling pathways that regulate NLRC4 expression.

\section{Materials and methods}

Sample collection. The Ethics Committee of Soochow University Affiliated Children's Hospital (Suzhou, China) approved the protocols for the present study. A total of 42 children aged between 1-6 years with confirmed bacterial septicaemia diagnosis were recruited in the current study. A total of 40 healthy children (age, 1-6 years), who underwent 
routine physical examination, served as the control group. Written informed consent was obtained from the parents of all children prior to enrollment in the current study. Blood samples were collected from each child and centrifuged at $1,000 \mathrm{x} g$ for $10 \mathrm{~min}$ to obtain the blood serum.

Cell culture. RAW264.7 macrophage cells were purchased from American Type Culture Collection (Manassas, VA, USA) and cultured in Dulbecco's modified Eagle's medium (DMEM; Invitrogen; Thermo Fisher Scientific, Inc., Waltham, MA, USA). The medium was supplemented with $2 \mathrm{mM}$ glutamine and $10 \%$ fetal bovine serum (FBS; Invitrogen; Thermo Fisher Scientific, Inc.). Cells were maintained at $37^{\circ} \mathrm{C}$ in a humidified atmosphere with $5 \% \mathrm{CO}_{2}$. LPS, and the inhibitors U0126, SP600125 and SB203580 were obtained from Sigma-Aldrich (St. Louis, MO, USA). LPS was dissolved in phosphate-buffered saline to concentrations of 100,500 and 1,000 ng/ml. U0126, SP600125, and SB203580 were dissolved in dimethyl sulphoxide (Sigma-Aldrich) to a final concentration of $20 \mu \mathrm{M}$. U0126, SP600125 and SB203580 were used to treat cells for $24 \mathrm{~h}$ at $5 \mu \mathrm{M}$.

Transfection. Transfection of scramble small interfering RNA (siRNA) and NLRC4 siRNA (Sangon Biotech Co., Ltd., Shanghai, China) was performed on RAW264.7 cells using Lipofectamine 2000 (Invitrogen; Thermo Fisher Scientific, Inc.) according to the manufacturer's protocol. Briefly, $0.1 \mathrm{nmol}$ siRNA and $5 \mu \mathrm{l}$ Lipofectamine 2000 reagent were separately diluted in $250 \mu 1$ Opti-MEM (Invitrogen; Thermo Fisher Scientific, Inc.), and incubated at room temperature for $5 \mathrm{~min}$. The two dilutions were then mixed and incubated at room temperature for an additional $20 \mathrm{~min}$. The DNA-Lipofectamine 2000 complex that was produced was added to $5 \times 10^{5}$ cells/well for $6 \mathrm{~h}$. The media was then replaced with fresh DMEM supplemented with $2 \mathrm{mM}$ glutamine and $10 \%$ FBS.

Enzyme-linked immunosorbent assay (ELISA). Cytokine levels in the culture media of RAW264.7 cells were determined using an ELISA assay. Mouse IL-1//IL-1F2 Quantikine ELISA kit and Mouse IL-18/IL-1F4 ELISA kit were purchased from R\&D Systems, Inc. (Minneapolis, MN, USA). Briefly, the samples to be measured or ELISA standards were pipetted into the wells of the plate and incubated at room temperature for $2 \mathrm{~h}$. Following washing, mouse IL-1 $\beta$ conjugate or mouse IL-18 conjugate was added to each well and incubated at room temperature for another $2 \mathrm{~h}$. Following washing, a substrate solution was added to each well, and the reaction was terminated by the addition of the stop solution from the kit. The optical density was measured at a wavelength of $450 \mathrm{~nm}$ using an AMR-100 microplate reader (Hangzhou Allsheng Instruments Co., Ltd., Hangzhou, China).

Reverse transcription-quantitative polymerase chain reaction $(R T-q P C R$ ). TRIzol (Invitrogen; Thermo Fisher Scientific, Inc.) was used for the extraction of RNA from the blood serum. The RNA was purified using the Transcript RNA CleanUp kit (Takara Biotechnology Co., Ltd., Dalian, China) and DNase I (Beyotime Institute of Biotechnology, Haimen, China) was used to cleave DNA. Reverse transcription-quantitative PCR was performed using One Step SYBR PrimeScript RT-PCR
$\mathbf{A}$

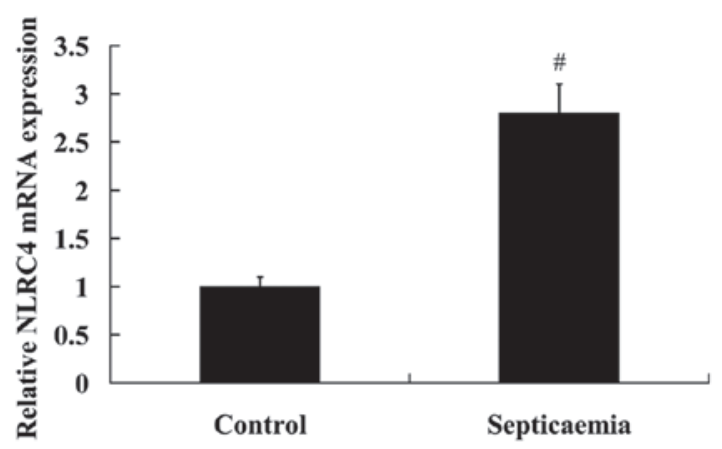

B

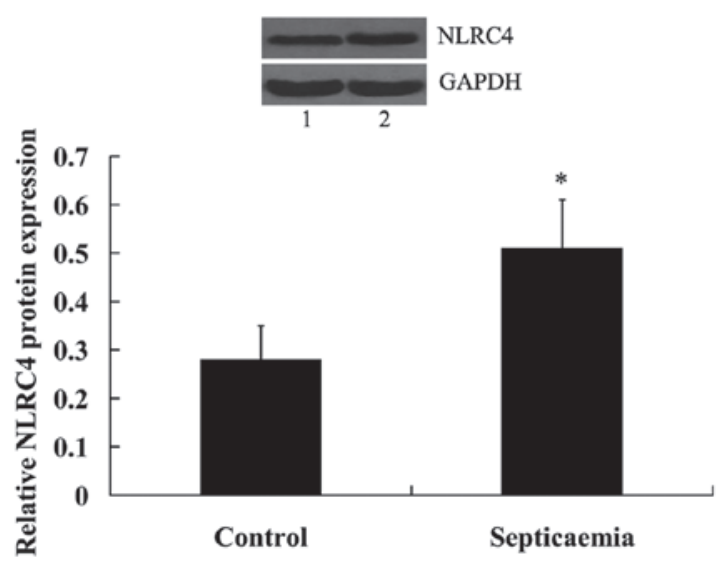

Figure 1. Expression levels of NLRC4 in the blood samples of normal controls and children with septicaemia. Expression levels of NLRC4 (A) mRNA and $(\mathrm{B})$ protein. Data are expressed as the mean \pm standard deviation. ${ }^{*} \mathrm{P}<0.05$ and ${ }^{\#} \mathrm{P}<0.01$ vs. the control. Lane 1, control; lane 2, septicaemia. NLRC4, NOD-like receptor family, CARD domain-containing protein 4.

kit II (Takara Biotechnology Co, Ltd.) according to the manufacturer's protocol. Primer sequences were as follows: forward, 5'-AGCTCAAAGGTTCAAGCCAA-3' and reverse, 5'-TGC GAGGTGCTTCATAACAG-3' for NLRC4; and forward, 5'-GTCAGTGGTGGACCTGACCT-3' and reverse, 5'-GGG TCTTACTCCTTGGAGGC-3' for GAPDH. PCR was performed on a ABI 7500 Fast Real Time PCR system (Applied Biosystems; Thermo Fisher Scientific, Inc.). The RT reaction was performed at $42^{\circ} \mathrm{C}$ for $5 \mathrm{~min}$. The PCR reaction conditions were: $95^{\circ} \mathrm{C}$ for $10 \mathrm{~min}$; followed by 40 cycles of $95^{\circ} \mathrm{C}$ for $30 \mathrm{sec}, 60^{\circ} \mathrm{C}$ for $30 \mathrm{sec}$; and $72^{\circ} \mathrm{C}$ for $20 \mathrm{sec}$. GAPDH served as an internal standard. The PCR was conducted at least three times and quantified using the $2^{-\Delta \Delta C q}$ method (14)

Western blotting. Total protein was extracted from the serum and the cells using radioimmunoprecipitation assay buffer (Beyotime Institute of Biotechnology). The protein concentration was determined using the Bradford protein assay kit from Bio-Rad Laboratories, Inc. (Hercules, CA, USA). The samples $(50 \mu \mathrm{g})$ were resolved on $10 \%$ SDS-PAGE at $200 \mathrm{~V}$ for $80 \mathrm{~min}$, and the proteins were transferred onto a polyvinylidene difluoride membranes (Bio-Rad Laboratories) by electroblotting. Following blocking with 5\% non-fat milk, the membranes were further incubated with the primary antibodies, including rabbit polyclonal anti-NLRC4 (1:800; cat. no. ab189593, Abcam, Cambridge, MA, USA), rabbit monoclonal anti-phospho-extracellular regulated protein 
A
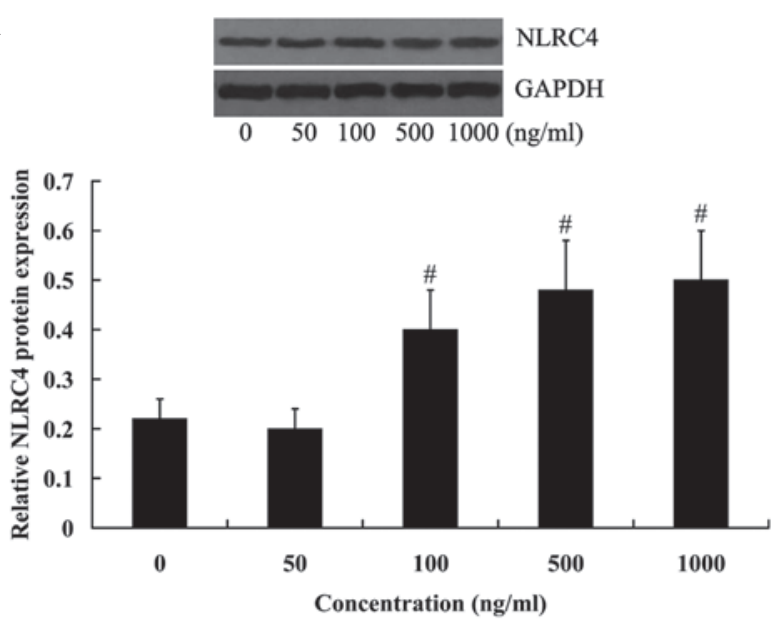

B
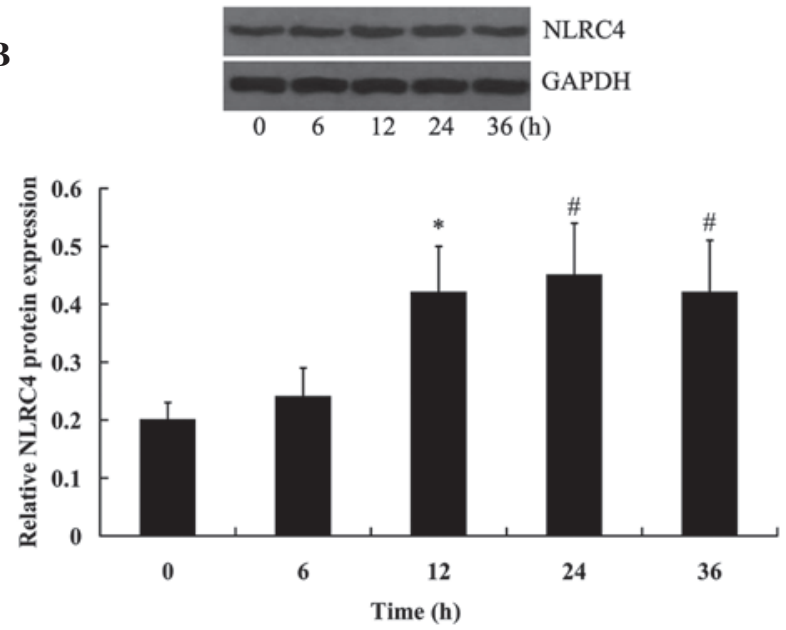

Figure 2. Effect of LPS on NLRC4 expression levels in RAW264.7 cells. (A) LPS induced NLRC4 expression in a (A) dose- and (B) time-dependent manner. Data are expressed as the mean \pm standard deviation. ${ }^{*} \mathrm{P}<0.05$, ${ }^{\#} \mathrm{P}<0.01$ vs. the $0 \mathrm{ng} / \mathrm{ml}$ or $0 \mathrm{~h}$ groups. LPS, lipopolysaccharide; NLRC4, NOD-like receptor family, CARD domain-containing protein 4.

kinase (ERK) 1/2 (1:1,000; cat. no. 4377; Cell Signaling Technology, Inc., Danvers, MA, USA), rabbit polyclonal anti-phospho-c-Jun N-terminal kinase (JNK; 1:1,000; cat. no. 9251; Cell Signaling Technology, Inc.), rabbit monoclonal anti-phospho-p38 (1:400; cat. no. 4631; Cell Signaling Technology, Inc.) and rabbit polyclonal anti-GAPDH (1:2,000; cat. no. bs-2188R; BIOSS, Beijing, China). The membranes were then washed with Tris-buffered saline containing $0.05 \%$ Tween 20 (Sinopharm Chemical Reagent Co., Ltd., Shanghai, China) three times prior to incubation with the goat anti-rabbit IgG horseradish peroxidase-conjugated secondary antibody (1:2,000; cat. no. bs-0295G; BIOSS). GAPDH served as a loading control. ECL Plus chemiluminescence detection kit from GE Healthcare Life Sciences (Chalfont, UK) was used for protein detection. The band intensity was quantified using Image $\mathbf{J}$ (imagej.nih.gov/ij/) and the experiments were independently performed three times.

Statistical analysis. All data are expressed as the mean \pm standard deviation and were analyzed using a Student's t-test for the comparison of two groups or analysis of variance followed
A
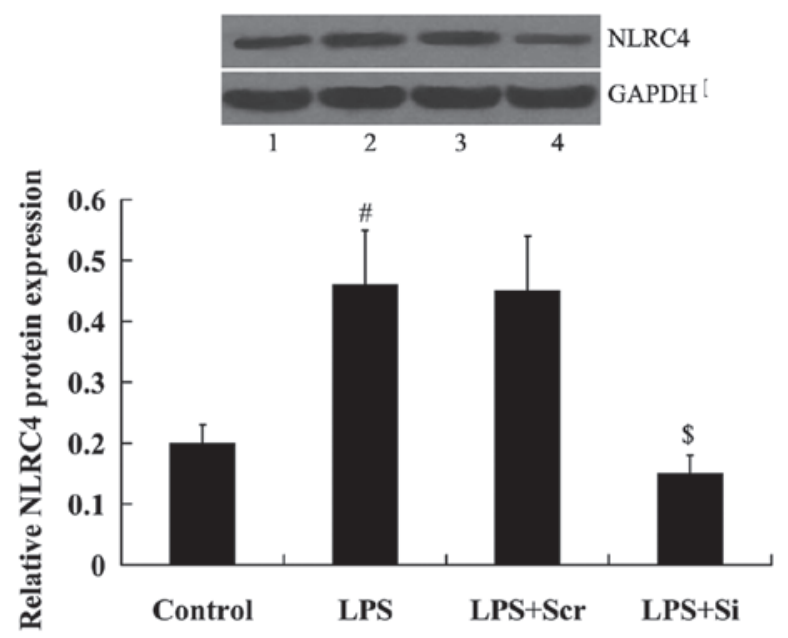

B
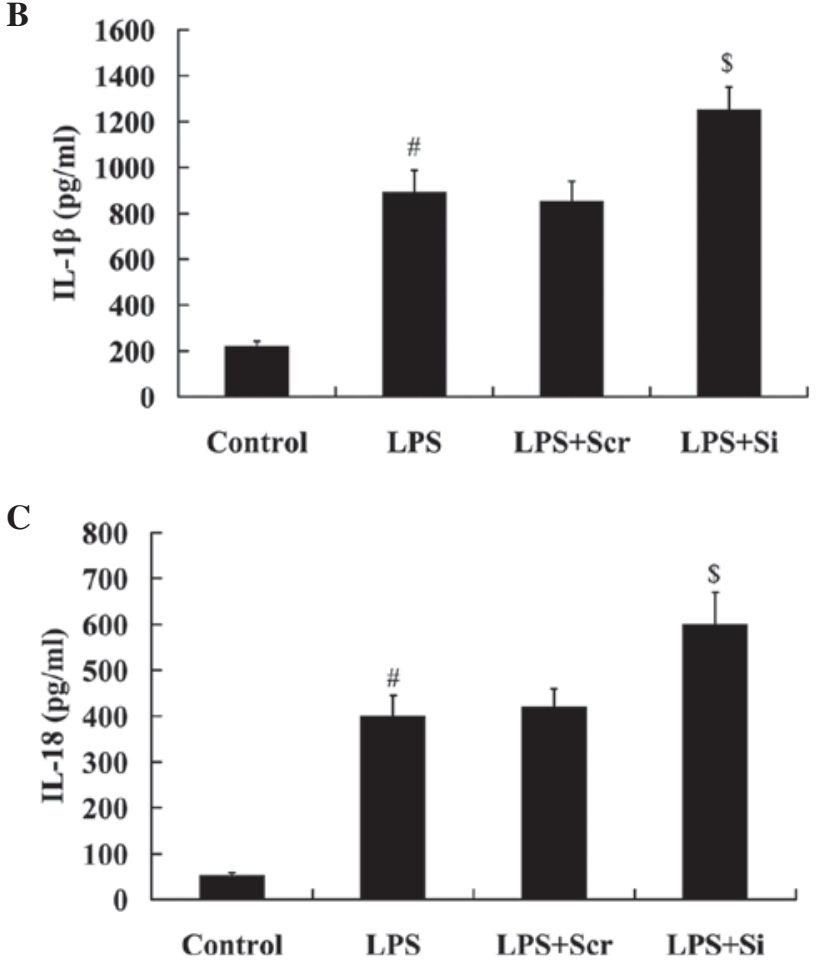

Figure 3. Effect of NLRC4 knockdown on LPS-induced cytokine production. Expression levels of NLRC4 in Raw264.7 cells following transfection with (A) NLRC4 siRNA and/or LPS treatment. (B) IL-1 $\beta$ and (C) IL-18 production in RAW264.7 cells following transfection with the NLRC4 siRNA and/or LPS treatment. Data are presented as the mean \pm standard deviation. ${ }^{\#} \mathrm{P}<0.01$ vs. the control group; ${ }^{\$} \mathrm{P}<0.01$ vs. the LPS $+\mathrm{Scr}$ group. Lane 1 , control; lane 2, LPS; lane 3, LPS + Scr; lane 4, LPS + Si. LPS, lipopolysaccharide; NLRC4, NOD-like receptor family, CARD domain-containing protein 4; IL, interleukin; Scr, scramble; Si, siRNA.

by least significant difference test for comparison of multiple groups. The statistical analysis was conducted with SPSS, version 19.0 (IBM SPSS, Armonk, NY, USA). P<0.05 was considered to indicate a statistically significant difference.

\section{Results}

NLRC4 expression increased in the blood serum of children with septicaemia. mRNA and protein expression levels of 
A
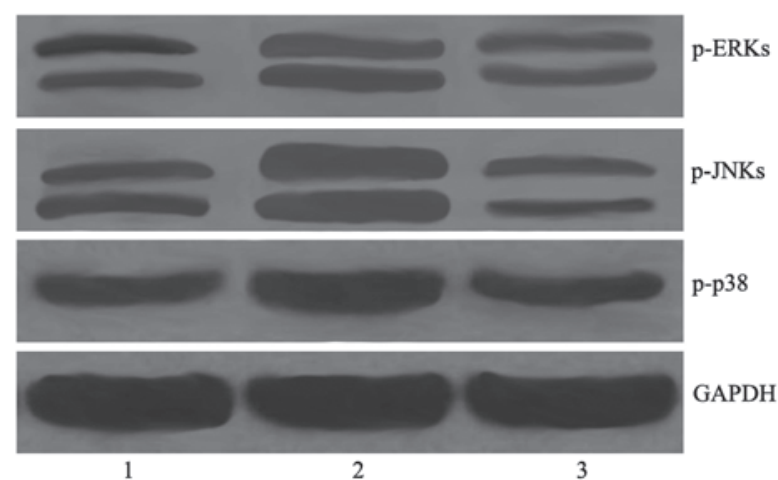

C

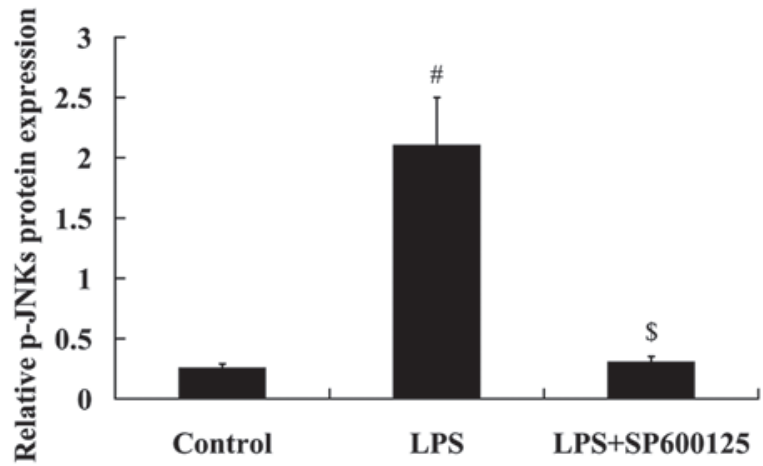

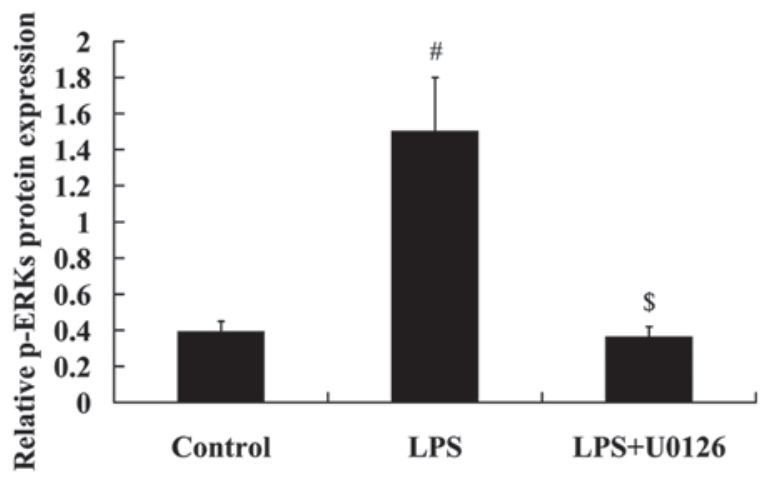

D

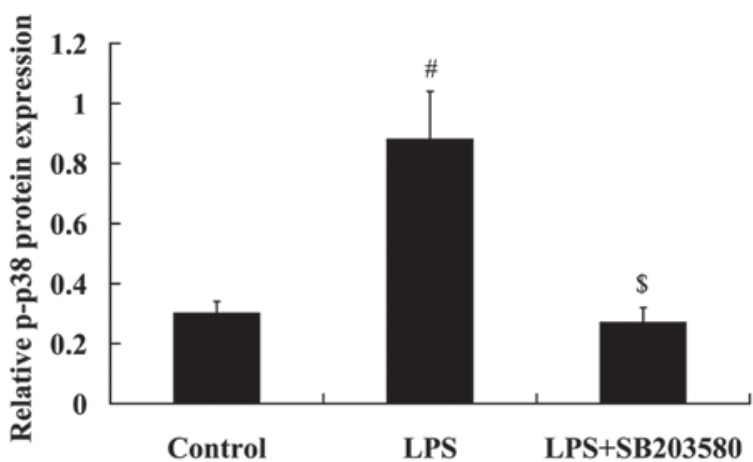

Figure 4. Effect of MAPK inhibitors on LPS-induced MAPK activation. (A) Western blot analysis of p-ERKs, p-JNKs and p-p38 in RAW264.7 cells following treatment with MAPK inhibitors. (B) Expression of p-ERKs in RAW264.7 cells following treatment with U0126. (C) Expression of p-JNKs in RAW264.7 cells following treatment with SP600125. (D) Expression of p-p38 in RAW264.7 cells following treatment with SB203580. Data are presented as the mean \pm standard deviation. ${ }^{\prime \prime} \mathrm{P}<0.01$ vs. the control; ${ }^{~} \mathrm{P}<0.01$ vs. the LPS group. Lane 1 , control; lane 2 , LPS; lane 3 , LPS + inhibitors LPS, lipopolysaccharide; MAPKs, mitogen-activated protein kinases; ERKs, extracellular signal-regulated kinases; JNKs, c-JUN N-terminal kinases; p, phosphorylated.

NLRC4 in blood serum were determined. The results from the RT-qPCR indicated that NLRC4 mRNA expression levels were significantly increased in the septicaemia group compared with the control group $(\mathrm{P}<0.01$; Fig. 1A). Consistently, the expression levels of NLRC4 protein were significantly upregulated in the blood serum of children with septicaemia $(\mathrm{P}<0.05$; Fig. 1B).

LPS-induced NLRC4 expression in RAW264.7 cells. RAW264.7 cells were treated with various concentrations of LPS for $24 \mathrm{~h}$, and then collected to investigate the effect of LPS on NLRC4 expression. As presented in Fig. 2A, LPS at the concentrations of 100,500 and $1,000 \mathrm{ng} / \mathrm{ml}$ significantly increased the expression of NLRC4 and reaching a peak value at $1,000 \mathrm{ng} / \mathrm{ml}(\mathrm{P}<0.01)$. RAW264.7 cells were treated with $500 \mathrm{ng} / \mathrm{ml}$ LPS for $6,12,24$ and $36 \mathrm{~h}$, respectively, it was determined that NLRC4 expression levels were significantly increased with prolonged cell incubation (Fig. 2B; $\mathrm{P}<0.05$ for $12 \mathrm{~h}, \mathrm{P}<0.01$ for 24 and $36 \mathrm{~h}$ ).

NLRC4 knockdown enhances LPS-induced cytokine production. To determine the importance of NLRC4 in mediating the effect of LPS on cytokine production, RAW264.7 cells were transfected with the NLRC4 siRNA and incubated with $500 \mathrm{ng} / \mathrm{ml}$ LPS for $24 \mathrm{~h}$. As indicated in Fig. 3A, NLRC4 expression was significantly decreased in the cells following transfection with NLRC4 siRNA $(\mathrm{P}<0.01)$.

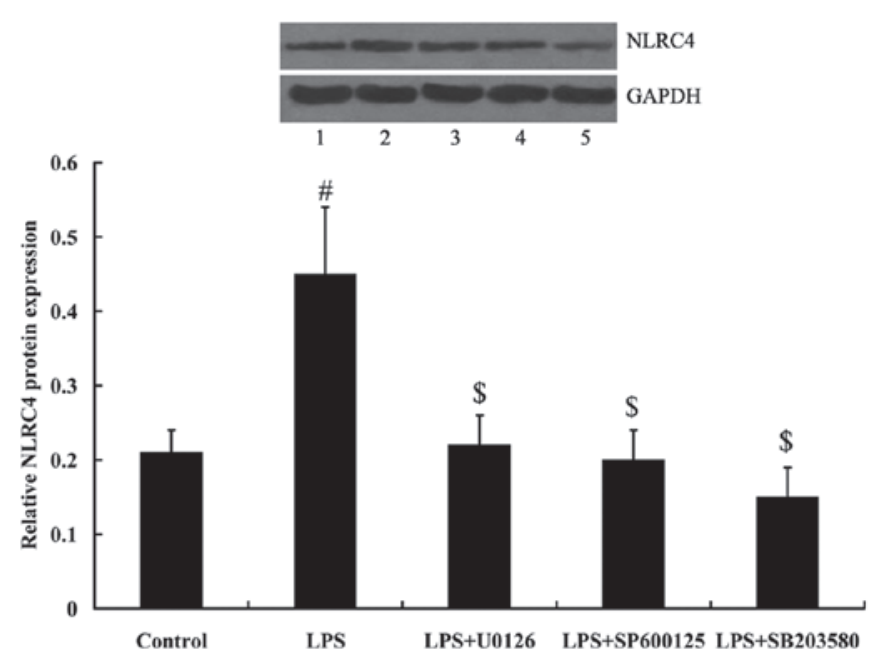

Figure 5. Expression of NLRC4 in RAW264.7 cells following treatment with LPS and MAPK inhibitors. Data are presented as the mean \pm standard deviation. ${ }^{\# P}<0.01$ vs. the control; ${ }^{\$} \mathrm{P}<0.01$ vs. the LPS group. LPS, lipopolysaccharide; NLRC4, NOD-like receptor family, CARD domain-containing protein 4; MAPKs, mitogen-activated protein kinases.

Notably, IL-1 $\beta$ and IL-18 production was significantly induced in Raw264.7 cells incubated with LPS $(\mathrm{P}<0.01)$. Furthermore, it was determined that this effect was enhanced by the transfection of NLRC4 siRNA (Fig. 3B and C). 
Mitogen activated protein kinases (MAPKs) mediated the effect of LPS on NLRC4 expression. To determine whether MAPKs were involved in the effect of LPS on NLRC4 expression, ERK inhibitor U0126, JNKs inhibitor SP600125, and p38 inhibitor SB203580 were added to treat RAW264.7 cells. As demonstrated in Fig. 4, MAPK signaling was activated in RAW264.7 cells under LPS treatment, as demonstrated by the increased expression of phosphorylated (p)-ERKs, p-JNKs and p-p38. However, MAPK signaling was inhibited in RAW264.7 cells following treatment with inhibitors. Furthermore, LPS-induced NLRC4 expression was attenuated by the treatment of MAPK inhibitors (all $\mathrm{P}<0.01$; Fig. 5).

\section{Discussion}

The present study, to the best of our knowledge, is the first to report that the expression of NLRC4 was significantly upregulated in the blood serum of children with septicaemia. This finding suggested that NLRC4 may exert an important function in infectious diseases. In vitro experiments were performed to investigate the importance of NLRC4 in the immune responses of macrophages, and the associated molecular mechanisms.

Bacteria, particularly Gram-negative bacteria, are the predominant causes of infection (15). LPS is the representative endotoxin on the outer membrane of Gram-negative bacteria (16). It has been established that LPS activates the inflammatory response and innate immune system in infection, and induces overproduction of pro-inflammatory cytokines (17).

In the present study, LPS-stimulated RAW264.7 cells were used to investigate the effect of NLRC4 on the production of IL-1 $\beta$ and IL-18. They are cytokines produced by macrophages and other cells under various stimuli. They are important mediators of the inflammatory response (18-21). In a previous study by Ceballos-Olvera et al (22), it was reported that $\mathrm{NLRC}^{-/-}$mice produced IL-1 $\beta$ and IL-18 in higher quantities than wild type mice. By contrast, DeSantis et al (23) reported that IL-18 was reduced in $\mathrm{NLRC}^{-/-}$mice. Consistent with the reports by Ceballos-Olvera et al (22), the current study determined that knockdown of NLRC4 enhanced the effect of LPS on IL-1 $\beta$ and IL-18 production. This may indicate that NLRC4 suppresses LPS-induced overproduction of inflammatory cytokines.

The MAPK signaling pathway is involved in a variety of physiological processes, including cellular growth, development, differentiation, stress and cell death (24-26). In addition, MAPKs are also associated with numerous innate immune responses (27-29). LPS may activate the MAPK signaling pathway and downstream transcription factors may be induced to regulate the release of large quantities of pro-inflammatory cytokines (30). The present study initially reported that LPS induces NLRC4 expression in a time- and dose-dependent manner. As MAPKs are important in inflammatory and immune responses, it was further investigated whether LPS regulates the expression of NLRC4 via the MAPK signaling pathway. ERK, JNK, and the p38 MAPK are three widely studied conventional MAPK signaling pathways and inhibitors of ERK, JNK and p38 were used in the present study to block the MAPK signaling pathway.
The results demonstrated that LPS-induced NLRC4 expression was reversed by the suppression of the MAPK signaling pathway.

These data support the hypothesis that LPS activates the MAPK signaling pathway in macrophages, thus resulting in the upregulation of NLRC4. However, NLRC4 inhibits IL-1 $\beta$ and IL-18 production, contributing to the anti-inflammatory response. To the best of our knowledge, the present study is the first to investigate the expression of NLRC4 in children with septicaemia. Furthermore, a novel molecular mechanism for NLRC4 regulation in LPS-induced RAW264.7 cells was elucidated. NLRC4 requires further investigation as a potential therapeutic strategy against infectious diseases.

\section{Acknowledgements}

The present study was supported by the Science and Technology Project of Jiangsu Province Department of Health (grant no. Z201406).

\section{References}

1. Misallati A, el-Bargathy S and Shembesh N: Blood-culture-proven neonatal septicaemia: A review of 36 cases. East Mediterr Health J 6: 483-486, 2000.

2. Meremikwu MM, Nwachukwu CE, Asuquo AE, Okebe JU and Utsalo SJ: Bacterial isolates from blood cultures of children with suspected septicaemia in Calabar, Nigeria. BMC Infect Dis 5: 110,2005

3. Geddes BJ, Wang L, Huang WJ, Lavellee M, Manji GA, Brown M, Jurman M, Cao J, Morgenstern J, Merriam S, et al: Human CARD12 is a novel CED4/Apaf-1 family member that induces apoptosis. Biochem Biophys Res Commun 284: 77-82, 2001.

4. Franchi L, Amer A, Body-Malapel M, Kanneganti TD, Ozören N, Jagirdar R, Inohara N, Vandenabeele P, Bertin J, Coyle A, et al: Cytosolic flagellin requires Ipaf for activation of caspase-1 and interleukin 1beta in salmonella-infected macrophages. Nat Immunol 7: 576-582, 2006.

5. Miao EA, Alpuche-Aranda CM, Dors M, Clark AE, Bader MW, Miller SI and Aderem A: Cytoplasmic flagellin activates caspase-1 and secretion of interleukin 1beta via Ipaf. Nat Immunol 7: 569-575, 2006.

6. Lightfield KL, Persson J, Trinidad NJ, Brubaker SW, Kofoed EM, Sauer JD, Dunipace EA, Warren SE, Miao EA and Vance RE: Differential requirements for NAIP5 in activation of the NLRC4 inflammasome. Infect Immun 79: 1606-1614, 2011.

7. Zhao Y, Yang J, Shi J, Gong YN, Lu Q, Xu H, Liu L and Shao F: The NLRC4 inflammasome receptors for bacterial flagellin and type III secretion apparatus. Nature 477: 596-600, 2011.

8. Kofoed EM and Vance RE: NAIPs: Building an innate immune barrier against bacterial pathogens. NAIPs function as sensors that initiate innate immunity by detection of bacterial proteins in the host cell cytosol. Bioessays 34: 589-598, 2012.

9. Poyet JL, Srinivasula SM, Tnani M, Razmara M, Fernandes-Alnemri T and Alnemri ES: Identification of Ipaf, a human caspase-1-activating protein related to Apaf-1. J Biol Chem 276: 28309-28313, 2001.

10. Miao EA, Ernst RK, Dors M, Mao DP and Aderem A: Pseudomonas aeruginosa activates caspase 1 through Ipaf. Proc Natl Acad Sci USA 105: 2562-2567, 2008.

11. Miao EA, Mao DP, Yudkovsky N, Bonneau R, Lorang CG, Warren SE, Leaf IA and Aderem A: Innate immune detection of the type III secretion apparatus through the NLRC4 inflammasome. Proc Natl Acad Sci USA 107: 3076-3080, 2010.

12. Brodsky IE, Palm NW, Sadanand S, Ryndak MB, Sutterwala FS, Flavell RA, Bliska JB and Medzhitov R: A yersinia effector protein promotes virulence by preventing inflammasome recognition of the type III secretion system. Cell Host Microbe 7: 376-387, 2010.

13. Warren SE, Mao DP, Rodriguez AE, Miao EA and Aderem A: Multiple nod-like receptors activate caspase 1 during listeria monocytogenes infection. J Immunol 180: 7558-7564, 2008. 
14. Livak KJ and Schmittgen TD: Analysis of relative gene expression data using real time quantitative PCR and the 2(-delta delta $C(T))$ method. Methods 25: 402-408, 2001

15. Luna CM, Rodriguez-Noriega E, Bavestrello L and Guzmán-Blanco M: Gram-negative infections in adult intensive care units of latin america and the Caribbean. Crit Care Res Pract 2014: 480463, 2014.

16. Moran AP, Prendergast MM and Appelmelk BJ: Molecular mimicry of host structures by bacterial lipopolysaccharides and its contribution to disease. FEMS Immunol Med Microbiol 16: 105-115, 1996

17. Takeuchi $\mathrm{O}, \mathrm{Hemmi} \mathrm{H}$ and Akira S: Interferon response induced by toll-like receptor signaling. J Endotoxin Res 10: 252-256, 2004.

18. Dennis VA, Jefferson A, Singh SR, Ganapamo F and Philipp MT: Interleukin-10 anti-inflammatory response to borrelia burgdorferi, the agent of lyme disease: A possible role for suppressors of cytokine signaling 1 and 3. Infect Immun 74 5780-5789, 2006.

19. Zediak VP and Hunter CA: IL-10 fails to inhibit the production of IL-18 in response to inflammatory stimuli. Cytokine 21: 84-90, 2003.

20. Kasama T, Miwa Y, Isozaki T, Odai T, Adachi M and Kunkel SL: Neutrophil-derived cytokines: Potential therapeutic targets in inflammation. Curr Drug Targets Inflamm Allergy 4: 273-279, 2005.

21. Brodsky IE and Monack D: NLR-mediated control of inflammasome assembly in the host response against bacterial pathogens. Semin Immunol 21: 199-207, 2009.
22. Ceballos-Olvera I, Sahoo M, Miller MA, Del Barrio L and Re F: Inflammasome-dependent pyroptosis and IL-18 protect against burkholderia pseudomallei lung infection while IL-1 $\beta$ is deleterious. PLoS Pathog 7: e1002452, 2011.

23. DeSantis DA, Ko CW, Liu Y, Liu X, Hise AG, Nunez G and Croniger CM: Alcohol-induced liver injury is modulated by Nlrp3 and Nlrc4 inflammasomes in mice. Mediators Inflamm 2013: 751374,2013

24. Plotnikov A, Zehorai E, Procaccia S and Seger R: The MAPK cascades: Signaling components, nuclear roles and mechanisms of nuclear translocation. Biochim Biophys Acta 1813: 1619-1633, 2011.

25. Runchel C, Matsuzawa A and Ichijo H: Mitogen-activated protein kinases in mammalian oxidative stress responses. Antioxid Redox Signal 15: 205-218, 2011.

26. Keshet Y and Seger R: The MAP kinase signaling cascades: A system of hundreds of components regulates a diverse array of physiological functions. Methods Mol Biol 661: 3-38, 2010.

27. Arthur JS and Ley SC: Mitogen-activated protein kinases in innate immunity. Nat Rev Immunol 13: 679-692, 2013.

28. Yang Y, Kim SC, Yu T, Yi YS, Rhee MH, Sung GH, Yoo BC and Cho JY: Functional roles of p38 mitogen-activated protein kinase in macrophage-mediated inflammatory responses. Mediators Inflamm 2014: 352371, 2014.

29. Tiedje C, Holtmann H and Gaestel M: The role of mammalian MAPK signaling in regulation of cytokine mRNA stability and translation. J Interferon Cytokine Res 34: 220-232, 2014.

30. Guha M and Mackman N: LPS induction of gene expression in human monocytes. Cell Signal 13: 85-94, 2001. 